ICAME Journal, Volume 42, 2018, DOI: 10.1515/icame-2018-0001

\title{
A tribute to Matti Rissanen
}

Sebastian Hoffmann ${ }^{1}$, Merja Kytö ${ }^{2}$, Terttu Nevalainen ${ }^{3}$ and Irma Taavitsainen $^{3}$

Trier University ${ }^{1}$, Uppsala University ${ }^{2}$ and University of Helsinki ${ }^{3}$

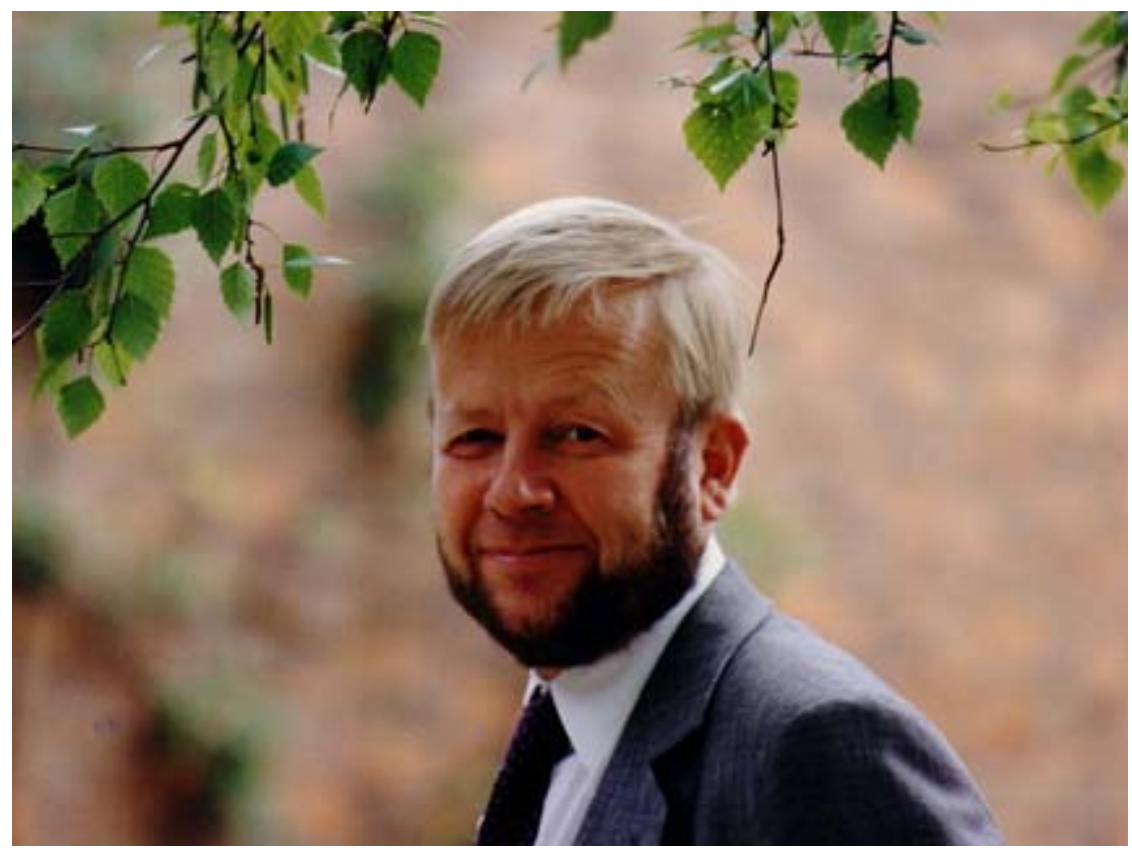

Matti Rissanen (23 June 1937-24 January 2018) ${ }^{1}$

Matti Rissanen (1937-2018) was Professor Emeritus of English Philology at the University of Helsinki. For more than three decades, his own professional development and the growth of ICAME - and the ICAME community - were closely intertwined. He joined ICAME in 1984 at the 5th ICAME conference in Windermere, where he presented plans for (and the early progress of) the Helsinki 
Corpus project: "In the autumn of 1983, a project was launched at the English Department of the University of Helsinki to compile an extensive corpus of English texts for the purpose of diachronic studies, primarily on the syntactic and lexical levels. [...] The Corpus will consist of extracts representing a variety of texts covering the period from the earliest Old English to the early 18th century." (Sue Blackwell's report on the conference, ICAME News 9 1985, p. 13). The project received plenty of encouragement and support from the participants. At that time this was a pioneering project, foreshadowing the future and work with early personal computers (e.g. Kaypro and Osborne) and floppy disks used for storing corpus texts. A team was recruited from the staff and doctoral students of the English Department to compile the diachronic part, with Merja Kytö as the research secretary. In retrospect, Matti acknowledged the value of the support from the ICAME community for his and his colleagues' activities in Helsinki at the "The History of ICAME" session at the 30th ICAME conference in Lancaster in $2009 .^{2}$

The seventh ICAME conference in Amsterdam (1986) saw the introduction of an ICAME Advisory Board, with Matti as one of its 12 members. The following year, he organized an early ICAME conference at Hanasaari, Espoo near Helsinki, on 21-24 May, 1987. Eager to exploit the latest developments in computer technology, Matti explored the possibilities of enhancing the facilities at Hanasaari. Among the novelties provided by IBM was that for the first time at an ICAME conference it was possible to show the contents of a computer screen to the audience via a white screen set up on the stage.

The 1990s proved a particularly busy period of ICAME-related activities for Matti. He participated in the Nobel Symposium on Corpus Linguistics organized by Jan Svartvik in Lund on 4-8 August, 1991. His contribution focused on the use of corpora in the historical domain. The diachronic part of the Helsinki Corpus was released in 1991 and the research volume Early English in the computer age, with team members' contributions based on the corpus, was published in 1993. A follow-up to the compilation project was launched, comprising members of the compiling team continuing their research on the corpus data. The outcome of this project crystallized in two research volumes published in 1997, English in transition and Grammaticalization at work. In 1995, the VARIENG research unit was founded. It was an Academy of Finland Centre of Excellence for twelve years (2000-2011) with Matti as the leader until his retirement in 2001, followed by Terttu Nevalainen.

Matti was among the scholars who significantly contributed to the development of the ICAME activities. After Stig Johansson withdrew from his role as coordinating secretary in 1996, the organization was consolidated by appointing 
an ICAME Chair and, over the coming years, formulating a constitution. At this time, the name of the organization was changed into the "International Computer Archive of Modern and Medieval English", very much "to recognize the flourishing of historical corpus work, which was in large measure due to the inspired leadership of Matti Rissanen" (Leech and Johansson 2009: 18). Matti was also nominated the Chair and led the ICAME Board in their work on the constitution. It was during his time as Chair that ICAME began to develop into an open organization, one willing to welcome new members to join the activities. This process has continued into the 21 st century, with open calls for paper on major mailing lists now being a matter of course. In recognition of his contributions to the organisation, Matti was nominated an Honorary Life Member of ICAME in 2006.

Matti was an early user of the ICAME corpora, and many of his publications bear witness to his interest in the use of electronic resources. For instance, for his article from 1979 on the position of only in Present-day written English, he used the Brown corpus, with some comparative material collected "from various British English sources, including a small sample of spoken English from the Survey of English Usage archives" (Rissanen 1979: 65). In one of his last publications, an article on "Ere and before in English historical corpora, with special reference to the Corpus of English Dialogues" (Rissanen forthcoming), he used a wide array of historical and present-day corpora to investigate the long history of English, focusing on "the rapidly increasing use of before and on the gradual decline of the use of ere in the history of English". In between the two abovementioned articles, he produced a great number of research articles, peerreviewed book chapters, (co)edited volumes, and handbook contributions. His activities reached far beyond the ones accounted for here (see the link to the University of Helsinki research database below).

In sum, Matti was an exceptional scholar - and a true "ICAMEr" right from the outset. To further honour his contribution to the field, his 1989 article "Three problems connected with the use of diachronic corpora" is reprinted in this issue of the ICAME Journal. Much of its content is still highly relevant, and it also showcases Matti's ability to inspire and encourage both novices and more experienced members of the corpus linguistics community. He did not do this in a didactic vein, but with humour and insight, which were among his great strengths. We shall miss him, but his work and our good memories of him will live on. 


\section{Selected publications by Matti Rissanen related to ICAME and the Helsinki}

\section{Corpus}

1979. Rissanen, Matti. On the position of only in Present-day written English. In S. Jacobson (ed.). Papers from the Scandinavian Symposium on Syntactic Variation (Stockholm Studies in English 52), 63-76. Stockholm: Almqvist and Wiksell.

1988. Kytö, Merja, Ossi Ihalainen and Matti Rissanen (eds.). 1988. Corpus linguistics, hard and soft: Proceedings of the Eighth International Conference on English Language Research on Computerized Corpora. Amsterdam: Rodopi.

1991. Helsinki Corpus, see

http://www.helsinki.fi/varieng/CoRD/corpora/HelsinkiCorpus/.

1993. Rissanen, Matti, Merja Kytö and Minna Palander-Collin (eds.). Early English in the computer age. Berlin: Mouton de Gruyter.

1997. Rissanen, Matti, Merja Kytö and Kirsi Heikkonen (eds.) English in transition. Berlin: Mouton de Gruyter,

1997. Rissanen, Matti, Merja Kytö and Kirsi Heikkonen (eds.) Grammaticalization at work. Berlin: Mouton de Gruyter,

Forthcoming. Ere and before in English historical corpora, with special reference to the Corpus of English Dialogues. Special issue of the Journal of Historical Pragmatics on "Dialogues in diachrony: Celebrating historical corpora of speech-related texts", edited by Merja Kytö and Terry Walker.

\section{For Matti Rissanen's other publications and research activities, see the TUHAT database:}

https://tuhat.helsinki.fi/portal/fi/persons/matti-rissanen(7a2f33ca-9a3a-4d2e-a570edfc1168d61f).html

\section{Notes}

1. This picture of Matti Rissanen was taken by Udo Fries in 1988.

2. Matti's speech was video-recorded by the conference organisers, along with the other contributions to the same session.

\section{Reference}

2009. Leech, Geoffrey and Stig Johansson. The coming of ICAME. ICAME Journal 33: 5-20. 